\title{
La educación rural en escenarios de paz y posconflicto. Un acercamiento al estado del arte
}

Rural education in scenarios of peace and post-conflict. An approach to the state of the art

Leidy Johana Trujillo Franco ${ }^{I}$

Universidad Católica de Manizales, Colombia https://orcid.org/0000-0002-9561-2143

Silvio Cardona González

Universidad Católica de Manizales, Colombia http://orcid.org/0000-0003-2865-9002

Artículo de revisión

Fecha de recepción: 21 de abril de 2018 Fecha de aceptación: 6 de diciembre de 2018

\section{Para citar este artículo}

Trujillo Franco, L. J., y Cardona González, S. (2019). La educación rural en escenarios de paz y posconflicto. Un acercamiento al estado del arte. Campos en Ciencias Sociales, 7(2), 175-218. DOI: https://doi.org/10.15332/25006681.4288

1. Magíster en Educación, docente de educación básica primaria en la Institución Educativa Zaragoza, Cartago, Valle, Colombia. Correo electrónico: leidyjtrujillo@hotmail.com

2. Doctor en Educación. Docente del Doctorado en Educación de la Universidad Católica de Manizales, Colombia. Profesor catedrático titular de la ESAP Caldas, Manizales, Colombia. Correo electrónico: scardona@ucm.edu.co 


\section{RESUMEN}

El presente artículo hace una revisión bibliográfica acerca de la educación rural en el marco del posconflicto en Colombia, y el papel que desempeña el docente en él. La revisión fue construida a partir de siete ejes temáticos, a saber: sujeto político como transformador social, educación rural, escenarios de paz y posconflicto, educación y posconflicto, docentes en escenarios de posconflicto, responsabilidades de la educación superior en el posconflicto, y educación rural y posconflicto. Sobre cada uno de los ejes temáticos se realizó un análisis basado en la sustentación teórica que los autores asumen con respecto a los temas de interés de la revisión, los cuales son: el docente como sujeto político, la educación rural, y los escenarios de paz y posconflicto en Colombia. Al final del documento, se presentan unas conclusiones que intentan dar una panorámica del estado del arte sobre educación rural y posconflicto en Colombia.

Palabras clave: educación rural, paz, posconflicto, docente, sujeto político.

\section{Abstract}

The following article makes a bibliographic review about rural education in the context of Colombia's post-conflict, as well as the role of the teacher in it. The review was built from seven topics: political subject as a social transformer, rural education, peace scenarios and post-conflict, education and post-conflict, teachers in post-conflict scenarios, superior education responsibilities in the post-conflict, and rural education and post-conflict. On each of these topics, an analysis is made based on theoretical support from the authors about the review's topics of interest: teacher as a political subject, rural education, and peace scenarios and post-conflict in Colombia. At the end of the document, a few conclusions are presented, which try to give a view of the state of art about rural education and post-conflict in Colombia.

Keywords: Rural education, peace, post-conflict, teacher, political subject. 


\section{INTRODUCCIÓN}

En el presente artículo se propuso un acercamiento al estado del arte, en el marco de una investigación en la cual se conjugaron siete factores de interés: sujeto político como transformador social, educación rural, escenarios de paz y posconflicto, educación y posconflicto, docentes en escenarios de posconflicto, responsabilidades de la educación superior en el posconflicto, y educación rural y posconflicto.

Con ello se busca conformar un estado del arte sobre esta temática relevante y controversial para el país en el momento presente y en los ańos venideros, además de ubicar un punto de partida para el desarrollo investigativo aplicado, en referencia a los tres factores en cuestión. Es determinante conocer de antemano qué tanto se ha hecho en el ámbito académico acerca del desarrollo de propuestas que apoyen la educación rural en un nuevo contexto de posconflicto; a partir de ahí, es posible identificar las configuraciones de este sobre cómo afrontar los retos por los que el Estado colombiano ha apostado con el tratado de paz, las políticas públicas que tiene en desarrollo y su aplicación en el ámbito educativo, reconociendo este último como factor esencial de transformación social.

Tres fuentes teóricas son clave para construir este artículo de revisión: a) los documentos emanados de los diálogos de paz entre las Farc-EP y el Gobierno nacional; b) una bibliografía básica sobre educación rural y, c) trabajos académicos acerca del rol docente en la sociedad. A partir de allí se definen los conceptos de conflicto, posconflicto, paz, educación, docente y educación rural. A lo largo de la exposición, se pondrán en discusión estas definiciones con los hallazgos producto de la revisión documental.

\section{Metodología}

La investigación bibliográfica que dio origen a la construcción del presente artículo, se abordó desde el tipo de investigación documental, para dar cumplimiento al objetivo planteado, el cual pretendió realizar un acercamiento al estado del arte, sobre la conjugación de tres factores de interés: el docente como sujeto político, la 
educación rural y los escenarios de paz y posconflicto en Colombia tras el acuerdo de paz firmado en noviembre de 2016 en la Habana, Cuba, desarrollados en los siete ejes temáticos previamente descritos.

Emplear la investigación documental para la elaboración de este artículo fue esencial, pues se configura como un elemento clave al momento de analizar los resultados de aquellas investigaciones desarrolladas en el medio académico, que son relacionales al tema de estudio.

Para recopilar los datos, se recurrió al análisis de fuentes secundarias de información, es decir, "la utilización de datos publicados y estructurados que consiste en analizar el contenido de los documentos previamente recolectados" (Cea D'Ancona, 1996, p. 220). Dicha técnica permitió enriquecer el trabajo investigativo dado que facilitó obtener diferentes tipos de hallazgos, lo que logró ampliar el conocimiento relacionado con el tema, además de identificar cuál es el alcance investigativo respecto al objeto de estudio.

Las principales fuentes de información fueron tomadas de artículos científicos a través del motor de búsqueda de la herramienta Google Scholar, la cual permitió redireccionar a las bases de datos de Proquest, Eric, Educator's Reference Complete, Redalyc, Scielo, Dialnet, revistas indexadas y repositorios de diferentes universidades nacionales e internacionales. Además, en revistas indexadas en Publindex y en el buscador especializado Google Académico, entre otros.

Con el fin de ampliar las posibilidades de la revisión, se combinaron los siguientes términos de búsqueda: educación, ruralidad, educación rural, escenarios de paz y posconflicto, prácticas pedagógicas, docencia y sujeto político.

Una vez revisada, depurada y organizada la información, de un total de 63 documentos se seleccionaron 50 confiables, según criterios de validez científica, pertinencia y actualidad (documentos elaborados durante los últimos cinco años). Los documentos identificados fueron utilizados para la construcción final del artículo, al presentar como resultado los hallazgos más significativos en torno al tema en cuestión. La 
mayor parte de estos estudios estuvieron relacionados con las siguientes temáticas: sujeto político como transformador social (1), educación rural (2), escenarios de paz y posconflicto (7), educación y posconflicto (21), educación rural y posconflicto (1), específicamente en el campo de la educación social para el desarrollo.

En dichas investigaciones se evidenció un fuerte énfasis en estudios que relacionan la educación como factor clave en los procesos que derivan de los escenarios de paz y posconflicto; al mismo tiempo, de estas investigaciones surgieron dos clasificaciones más que se consideran parte de esta temática: los docentes en escenarios de posconflicto (2) y las responsabilidades de la educación superior en el posconflicto (3).

Finalmente, se procedió a realizar la síntesis y organización de los datos a través del ordenamiento y combinación de la información compendiada dentro de cada título o subtítulo propuesto. El análisis de la información recolectada fue hecha con base en la fundamentación teórica emanada de las lecturas mismas, así como de la mirada personal (sustentada igualmente en fuentes autorizadas que por motivos de espacio y objetivos del artículo no se expone aquí) sobre el asunto en particular. Como ejes de análisis se tuvieron en cuenta los conceptos de conflicto, posconflicto, paz, educación, docente y educación rural.

\section{Resultados}

\section{La investigación académica dentro del marco de la educación y el posconflicto en Colombia, además del rol ejercido por los docentes}

Al abordar las temáticas relacionadas con la movilización investigativa sobre el posconflicto colombiano y el reto de la educación frente a los nuevos escenarios que implican la búsqueda de la paz, se encuentran algunos estudios que intentan recabar cómo esta nueva dirección contiene oportunidades de transformación del tejido social, teniendo en cuenta un precedente significativo de generaciones que han surgido en un contexto de violencia en el país. 
Si bien es cierto que existen estudios sobre el conflicto, es muy poco el avance investigativo aplicado si se habla de un posconflicto, pues esta condición solo surge como un hecho dado tras la firma del acuerdo de paz en el ańo 2016. Por lo tanto, la mayoría de los estudios aquí relacionados son de carácter reflexivo e hipotético, en los cuales se rescatan el bagaje literario y bibliográfico sobre aspectos relativos a la paz y la educación. En este sentido, es mucho menos lo que se puede encontrar específicamente sobre estudios relacionales a la educación rural y el posconflicto.

Tras la conjugación de búsqueda de los términos educación rural y posconflicto, se encuentran investigaciones que generalizan el objeto de estudio, y que bien cooperan en la adquisición de una aproximación a los temas que la rodean:

\section{1) Sujeto político como transformador social}

Desde la visión del docente como sujeto político en el entorno educativo rural, no se encuentran investigaciones pertinentes y actuales para destacar; sin embargo, en el proceso de búsqueda se identificó un estudio que puede delimitar las bases teóricas para aproximar el conocimiento sobre la función del sujeto político como movilizador de los cambios sociales.

El estudio se denomina "La crisis de la sociedad y la construcción del sujeto político desde la perspectiva de Durkheim, Tönnies y Weber" (Berardi, 2015), en el cual se analiza cómo los mencionados teóricos confluyen en la idea de un sujeto político "como actor capaz de evitar los males suscitados en la sociedad, [lo que] nos pone en el desafío no solo de encontrar al agente sino también de interpretar su accionar y las herramientas que pone en marcha" (p. 181).

En la línea argumental de este autor, el momento político actual, marcado por una desintegración de los valores comunitarios, exige recuperar los pilares sociales de la premodernidad sin que esto signifique volver al pasado; el reto es conservar los logros de la Modernidad sin tener que pagar el precio de la decadencia moral y el individualismo a ultranza. De allí la necesidad de recurrir a los clásicos de la sociología para dar forma al sujeto político que deba encarnar este reto. 
La interlocución entre los tres autores que Berardi acoge se encuentra con el hilo conductor del tránsito de la comunidad a la sociedad en el marco de la consolidación del proyecto moderno. Ahora, si bien los tres autores se refieren a este hecho, difieren en lo que respecta a la valoración de las trazas de premodernidad. Para Weber (2008), la acción social propia de la premodernidad está dominada por lo tradicional como rasgo de irracionalidad, y de hecho como antítesis de la acción social racional con arreglo a fines, arquetipo de la Modernidad. Por el contrario, para Tönnies (1942) la tradición es el elemento clave para construir el sujeto político que rescate la sociedad moderna de su crisis. Esta idea es cercana a la expuesta por Durkheim (1997) en relación con las formas religiosas como fuente de la consciencia colectiva que contribuye a mantener unidos los lazos comunitarios en medio de la expansión de la sociedad moderna, en ocasiones bajo la forma de la coerción. La apuesta de Weber para salvar la crisis social no pasa entonces por los elementos tradicionales de Tönnies y Durkheim, sino por lo que él denomina el "sentimiento subjetivo de los partícipes de construir un todo” (en Berardi, 2015, p. 187), es decir, a través de la acción social individual.

Berardi (2015) concluye que el sujeto político en la perspectiva de la comunidad como proyecto utópico político, no es un sujeto determinado, construido y consolidado; es un actor en constante construcción, en tanto su principal función es reconstruir y reinventar los elementos que permiten la unidad de los individuos por medio de los lazos sociales, los cuales deben sostenerse por medio de un conjunto de valores morales y las tradiciones, que son modificadas y alteradas constantemente a medida que el desarrollo de la sociedad avanza. Así también, de forma recíproca, los devenires sociales y las interacciones sociales gestionan la construcción misma del sujeto político.

La tríada de autores que Berardi (2015) compila permite sostener que la construcción de un sujeto político que contribuya a la transformación social, con el objetivo de consolidar un proyecto más comunitario y humano y menos individualista e instrumental, es posible en la medida que se conserven y potencien los rasgos más loables de la tradición y la moralidad colectiva. La visión del propio Berardi va en la vía de lograr dicho cometido, el cual hunde sus raíces en los procesos de socialización y en la formación de los agentes sociales, en otras palabras, en la escuela como institución y en el docente como guía fundamental de dicho proceso. 


\section{2) Educación rural}

Siendo un foco de interés para este estudio, se destaca la educación rural como un factor integral de desarrollo para las comunidades que generalmente están relegadas de las políticas sociales, dada la brecha de inequidad constante que en países como Colombia se dificulta superar. La población rural resulta, para un escenario de conflicto interno, un objetivo que presenta la mayoría de condiciones de vulnerabilidad, y por lo tanto un blanco para los grupos terroristas que propenden por ejercer poder en territorios aislados, tal como lo han hecho durante años los actores del conflicto en Colombia.

La educación es la clave para la transformación social. Por lo tanto, se busca visualizar cómo esta puede aportar al restablecimiento de la sociedad rural, además de considerar cómo el docente desde su actuar se adecúa a las condiciones que este panorama implica.

Los hallazgos investigativos referentes a esta temática fueron escasos, sin embargo se lograron identificar dos estudios actuales adelantados en los últimos cinco años. El primero aborda una evaluación de la educación rural en Chile, desarrollado por Raczynski1 y Román (2014), en el cual se puede evidenciar un análisis de la política educativa en los países iberoamericanos en contextos rurales.

De forma generalizada, la educación rural se caracteriza por una debilidad en la formación docente, las escuelas unidocentes, las aulas multigrado, la extraedad de los estudiantes, la precariedad de los recursos y la deficiente infraestructura, problemáticas que se ahondan cada vez más por las situaciones de vulnerabilidad, dispersión y aislamiento; todo ello induce a efectos como la deserción escolar, el bajo rendimiento escolar, el escaso desarrollo de competencias y la ampliación de las brechas de inequidad social (Raczynskil y Román, 2014). Es por ello que las tasas de analfabetismo en estas zonas difícilmente se superan y las condiciones de vida van en declive.

El estudio en referencia concluye que, pese a la importancia que tiene la educación rural para los países, esta adolece de serias dificultades de funcionamiento por estar 
inmersa en la precariedad y escasez que se presenta en dichos entornos de las naciones estudiadas. La educación rural es un fenómeno que se encuentra relegado, no solo desde la política de los Estados, sino también por parte de la comunidad académica y la investigación, toda vez que constituye un campo poco explorado por esta.

Lo anterior concuerda con lo expresado por Perfetti (2004) en el informe conjunto de la Organización de las Naciones Unidas para la Alimentación y la Agricultura (FAO) y su homóloga para la Educación, la Ciencia y la Cultura (Unesco), denominado "Educación para la población rural en Brasil, Chile, Colombia, Honduras, México, Paraguay y Perú". En el apartado dedicado a Colombia, el autor deja claro el estado de la cuestión, a partir de una rigurosa revisión bibliográfica, sobre las condiciones de precariedad del campo colombiano, y particularmente de su componente educativo, afirmando que:

En cuanto a la educación para la población rural, se corrobora el aumento de las tasas de alfabetismo, escolaridad promedio y asistencia escolar durante este período. En materia de calidad, las escuelas y estudiantes rurales han mostrado avances importantes, los cuales se deben principalmente a la expansión y consolidación de modelos educativos concebidos para estas zonas, como el caso de Escuela Nueva, el Sistema de Aprendizaje Tutorial - SAT, entre otros. No obstante, la magnitud de la brecha educativa del sector rural con su contraparte urbana es aún bastante alta, con lo cual los avances mostrados no han sido suficientes para asegurar el mandato constitucional de ofrecer educación a toda su población. (Perfetti en FAO - Unesco, 2004, p. 167).

En una orilla diferente a la de los trabajos anteriormente citados, se resalta el segundo estudio identificado, el cual se titula "Pedagogía y calidad de la educación: una mirada a la formación del maestro rural” (Cossio, 2014), que proporciona una reflexión crítica y dialógica sobre el saber pedagógico y la calidad en el contexto escolar, y los desafíos que el docente rural asume frente a la calidad educativa, teniendo en cuenta las precarias condiciones en las que desarrolla su labor.

Sin embargo, cabe destacar que Cossio (2014) involucra en su discurso la ruralidad como un concepto que rompe los paradigmas de lo que se concibe como tal y 
propone identificar las nuevas dinámicas que se dan en este entorno y cómo se han modificado las características tradicionales, según las tendencias de la globalización.

En ese sentido, el autor recalca el surgimiento de nuevas posibilidades para fortalecer la educación rural mediante procesos de gestión que promuevan el saber pedagógico y lo desarrollen en función de las necesidades y las condiciones contextuales, flexibilizando el currículo y las estrategias pedagógicas, de acuerdo con las tradiciones del territorio y reforzando una "formación coherente a su realidad inmediata, sin desconocer lo global" (p. 21).

El autor llega a la conclusión de que la calidad es la herramienta que moviliza la trasformación del sistema educativo. Propender por ella desde el ejercicio docente es lo que podría posibilitar el éxito de los sujetos educables en los entornos donde estos se forman, desde su reconocimiento, valoración y desde las exigencias de la misma sociedad.

De forma semejante se expresa Bustos (2008) cuando se refiere al tipo de formación y componente actitudinal de los docentes rurales, partiendo de un estudio de caso en Andalucía, España. La revisión documental que realiza el autor le permite afirmar que la formación pedagógica que reciben los futuros docentes, y la que recibieron los profesores en ejercicio, es insuficiente para los retos particulares que impone la educación rural, lo cual va en concordancia con una visión de Estado centrada en la ciudad y con el distanciamiento entre este y el campo, producto de los procesos de industrialización y burocratización modernos, de los que la escuela no es ajena.

También menciona la actitud de los docentes hacia aspectos de la educación rural como las aulas multigrado, frente a los cuales se observa nuevamente una formación de espaldas a dicha realidad, ya que la mayoría de los profesores manifiesta preferir las aulas unigrado, en concordancia con el tipo de educación superior que recibieron. Por otro lado, destaca como rasgo positivo el acercamiento que se da entre docentes, estudiantes y padres de familia, mucho más estrecho que en la ciudad, dadas las características sociales de ambos contextos. En este último aspecto, Bustos concuerda 
con autores como Cossio que asumen al profesor como agente de cambio en determinados contextos culturales.

De lo expuesto en las líneas precedentes se puede deducir que ha sido una constante de los Estados occidentales mantener en el ostracismo a la educación rural. Aunque difieren en grado, en general las naciones democráticas, particularmente las latinas, han mantenido niveles de abandono estatal hacia el campo y la formación de los ciudadanos que lo habitan. En todos los casos se ha encontrado como constante los procesos de modernización como factor para mantener el campo como despensa de la ciudad industrializada y burocratizada, en cuyo caso la inversión en educación parece fútil. Se olvida, sin embargo, que una comunidad rural educada puede redundar en mejores resultados en los oficios que sus habitantes desempeñan, particularmente en la cualificación y modernización del campo, reto trascendental en estos días, sin olvidar el derecho inalienable de todo ser humano a la educación.

\section{3) Escenarios de paz y posconflicto}

Al hablar de escenarios de paz y posconflicto es necesario tener memoria, recordar aquello que ha marcado la historia del país y proyectar aquello que se quiere lograr. Para esto es importante abordar diferentes estudios que estén en relación con la temática.

Uno de ellos es "Justicia nosótrica para la paz: desde la memoria hacia la utopía" (Meza, 2016), en el que el autor evoca la realidad de injusticia que ha vivido y vive América Latina como un laboratorio de violencia, en el contexto de una economía sacrificial y de una cultura del olvido, escenario que posibilita la justicia, pero vista desde la perspectiva de los pueblos amerindios, los cuales aún conservan y viven desde la lógica del nosotros. Nuestras sociedades son como un "laboratorio vicioso de la cotidianidad de la violencia” (Bergmann, 2011, p. 8), donde vivimos - pero la mayoría no convivimos-.

La violencia institucional se respira por todos lados, violencia de un "sistema" legal-institucional, pero injusto e inhumano, como extraña dictadura sin rostro, que se oculta tras las promesas de bienestar, riqueza, progreso, libertad, seguridad, 
democracia; mientras continúa sacrificando la justicia, la solidaridad y hasta el equilibrio ecológico planetario en el altar sangrante del lucro sin límites y sin consciencia (Michel, 2003, p. 46).

Teniendo en cuenta lo planteado por Meza (2016) referido a que en la sociedad se vive pero la mayoría no convive; es dable concluir que esta es una realidad inherente del ser humano en esta época, que se caracteriza por la indiferencia, el olvido y la injusticia. Las sociedades se acostumbraron a vivir en medio del conflicto y no solamente referido al conflicto armado; también conflictos sociales que afectan la sana convivencia de aquellos que se encuentran en comunidad.

Por su parte, Meza (2016) manifiesta en su documento que

[...] la aparición repentina de un problema, de un conflicto, de una falta frente a la armonía comunitaria, conduce necesariamente a la presencia del nosotros como principio organizativo de solución, a una especie de "inteligencia colectiva", que no se agota solo en la inteligencia, sino que asume tanto el cuerpo como sus sentimientos. Por eso, todos se movilizan espontáneamente en forma nosótrica, desde cuatro principios fundamentales, como son la pluralidad, la diversidad, la complementariedad y el antimonismo, y configura desde ellos todo su comportamiento en la comunidad y, por ende, desde la comunidad hacia otras comunidades. Todos sienten reflejado su pensar y opinar en la voz nosotros, como algo que nace no de uno solo sino de la diversidad. (pp. 46-47).

Este planteamiento hace pensar en una nueva oportunidad para el Estado colombiano desde la ética, los valores, la democracia y la participación, para ir asumiendo roles y empoderamiento de su propio entorno de una manera justa.

También en una perspectiva comunitaria, pero con aristas diferentes, Marín (2017) presenta en su artículo "Construcción de paz en escenario de violencia intracomunitaria. Estudio de caso Sierra de la Macarena (Meta-Colombia)", una mirada hacia el interior de las comunidades que durante años padecieron tanto 
el abandono del Estado como los avatares del conflicto armado y las presiones de los alzados en armas. La autora hace una distinción entre la visión tradicional del conflicto, en la que de un lado están las víctimas civiles y del otro están los victimarios armados, y una perspectiva peculiar en la que los civiles pueden ser al mismo tiempo víctimas y victimarios, según sea el rol social que desempeñen en un momento determinado y en relación con otros tipos de actores, lo que trasciende la perspectiva jurídica de la justicia transicional.

A través de relatos de vida y entrevistas en profundidad, la autora logra concluir que

La implementación territorial de los acuerdos de paz y la prevención de las violencias en el posconflicto, deberán pasar, entre otras cosas, por la recuperación de los tejidos comunitarios. Como estrategia y con el concurso de las comunidades se debe promover la desnaturalización de la violencia y construir instancias de perdón, mediante la participación activa y el reconocimiento de todos los actores implicados en la violencia. Solo mediante el trámite de la violencia intracomunitaria es posible pensar en el silenciamiento definitivo de los fusiles en aquellas regiones afectadas por el conflicto armado. (p. 214).

Lo anterior permite marcar una diferencia con planteamientos como los de Meza (2016), en los que la visión de construcción comunitaria de escenarios de paz pasa por la utopía de la organización social cuasifamiliar. Más aún, Meza deja de lado lo que sí asume Marín: las verdaderas dimensiones de la Colombia profunda, que en la mayoría de los casos escapa a las dinámicas de las comunidades indígenas.

Por su parte, en la tesis doctoral denominada "Retorno y paz en contextos de conflicto. Análisis desde el enfoque de la vulnerabilidad social del caso El Carpintero (Colombia)" de Edwar Salamanca (2017), se busca entender los procesos de desplazamiento forzado desde la categoría analítica del destierro. A su vez, los procesos de retorno van más allá de un proceso migratorio de movilidad, y atraviesan dimensiones relacionadas con tres niveles: los riesgos-activos, la inequidad-desigualdad y la exclusión-pobreza. En dichos niveles, el territorio es la unidad de análisis fundamental para comprender 
la vulnerabilidad social de la población desterrada. Este estudio permite observar que para el caso colombiano la vulnerabilidad de las víctimas ha sido abordada desde un enfoque limitado que emerge de la relación del campo humanitario y el Estado.

Teniendo en cuenta lo anterior, se vislumbra la problemática social y económica que presenta el territorio colombiano en su necesidad de buscar un modelo económico que permita alcanzar otros niveles de desarrollo en los cuales no sea marginada la población, especialmente quienes habitan en territorios rurales, y en consecuencia que no se continúen perpetuando aquellos círculos de pobreza que limitan a la sociedad colombiana y conllevan a la desigualdad social, que es una de las razones por las cuales ha permanecido el conflicto.

Además, el enfoque de vulnerabilidad social permite pensar la paz desde escenarios de riesgo. Asumir esto es clave en la aplicación de políticas de corte transicional, en las que se deben canalizar esfuerzos para evitar la probabilidad de ocurrencia de nuevas violencias en los conflictos por la tierra que atraviesa el retorno de la población desterrada. El punto de convergencia con el análisis de Meza (2016) estriba en que ambos planteamientos abordan un tipo de justicia basada en el sentido de comunidad. No obstante, la comunidad analizada por Salamanca no llega a los niveles de nosotridad de lo expuesto por Meza, lo cual ha derivado en falta de organización entre las víctimas o de fragmentación entre las ya existentes, en muchos casos por razones partidistas exógenas al interés de la comunidad. Así mismo, el tipo de justicia planteado en el análisis de Marín (2017) asume tanto la vertiente vertical o estatal como la horizontal o comunitaria, mucho más compleja que la primera.

Para llegar a una transformación de los territorios y asegurar nuevos escenarios de paz, es fundamental retomar lo que plantea Arévalo (2014) en su documento "Construcción de paz y un nuevo modelo de construcción de Estado: una lectura de los dos primeros acuerdos de la Habana”, en el que afirma que el proceso de construcción de la paz tendrá que estar asociado a cambios en el papel del Estado y en su relación con la sociedad, así como a cambios en los incentivos para que los actores del conflicto no lleguen a promover la violencia en los próximos ańos. 
Según Arévalo (2014), desde una perspectiva más general, el enfoque de construcción diferenciada de Estado está en consonancia con las transformaciones globales de las últimas décadas, que inducen a las unidades subnacionales a jugar un papel cada vez más protagónico en la vida de sus países. En particular, el componente transversal de participación ciudadana permite construir la paz "desde abajo" y recoge elementos esenciales de la democracia deliberativa a partir del efecto positivo que esta puede llegar a tener en sociedades divididas.

En otra línea argumental del asunto, y si se amplía la mirada a los demás países que han pasado por la guerra y el conflicto armado, como es el caso en Centroamérica de el Salvador, Guatemala y Nicaragua, se puede evidenciar que la terminación del conflicto va más allá de la firma de un acuerdo, ya que en el estudio de Devia, Ortega y Magallanes "Violencia luego de la paz: escenarios de posconflicto en Centroamérica" (2014), se demuestra la necesidad de redefiniciones profundas en cuanto a la capacidad institucional del Estado y en cuanto a la generación de identidades positivas dentro de la población. El desafío principal no es conseguir la firma de la paz, sino la redefinición del Estado como tal y su reconstrucción bajo nuevos principios y valores que permitan la recuperación de la economía, la inclusión social y la disminución de la desigualdad.

Como bien lo expresan los autores, el problema del conflicto no es solamente la entrega de las armas. Este incluye también el planteamiento de nuevas políticas públicas o de Estado que apunten a los problemas estructurales del país, que tienen que ver principalmente con el modelo de desarrollo que se implementa y que más que dar prioridad al desarrollo económico, debe ir en gran medida hacia el desarrollo social y humano, lo cual se logra a partir de la educación como pilar fundamental para la construcción de sociedad a través de las interacciones de los sujetos.

En relación con el planteamiento anterior, pero dando entrada a un análisis más específico en lo que respecta a la institución educativa, Sotelo, Castellanos y Rodríguez (2017) en su artículo "La paz: una oportunidad de desarrollo social", plantean que la educación es una de las actividades comunes que la sociedad debe promover para fortalecer las capacidades de un grupo humano, puesto que esa capacidad es 
netamente personal pero afecta de manera importante al colectivo. Por lo anterior, se puede afirmar que la pobreza no es necesariamente la carencia de bienes o riqueza; es en realidad la falta de capacidad.

Sotelo, Castellanos y Rodríguez (2017) afirman que la educación es un elemento transformador desde el hogar hasta las naciones. En lo social, la educación es definitiva para mantener el tejido social y sustentar el patrimonio político y cultural.

Por otro lado, los autores hablan sobre la educación, y en especial la educación rural, en la que los docentes en comunidades pequeñas se convierten en líderes influyentes en todas las situaciones, pero su labor se ve condicionada por aspectos como el aislamiento de otros docentes por las distancias físicas importantes, las dificultades de acceso a la actualización en actividades pedagógicas o didácticas y las difíciles condiciones de acceso a los servicios públicos, que restringen la implementación de la tecnología para solventar esta limitante. Más grave aún es el hecho de que tienen a su cargo muchas veces toda la educación básica primaria de los asistentes a la escuela. En esta coyuntura nacional, la educación cobra importancia ya que a través de ella es posible potenciar actitudes existentes en todas las personas o transformarlas en capacidades de mucha índole, que pueden contribuir a cambiar la situación actual de la sociedad rural; de esta manera, se aporta a procesos de paz en comunidades víctimas de la violencia, algo que la exposición de Devia, Ortega y Magallanes (2014) solo trae de manera general y estructural.

Para complementar y reafirmar lo anterior, Barreto (2015) en el documento "El programa de desarrollo y paz del Magdalena Medio: ¿̨un modelo de construcción de paz para el postconflicto en Colombia?”, manifiesta que la construcción de una paz duradera, sostenible y positiva implica un proceso mucho más largo y que requiere la participación de muchos más actores de la sociedad, más allá del Estado y de los actores armados. Es un proceso paulatino y progresivo que se juega a varias escalas y niveles e implica la participación amplia de la población.

En una clave más cercana a la de Devia, Ortega y Magallanes (2014) que a la de Sotelo, Castellanos y Rodríguez (2017), este proceso de construcción de nuevos escenarios de paz lleva a que todos los sujetos que hacen parte de la sociedad integren y busquen 
el bien común y desde aquellas experiencias e historias de vida reconstruyan el tejido social desde lo micro y hasta conformar lo macro.

De esta manera queda evidenciado que este proceso va en doble vía; es decir, el Estado es el que debe garantizar las políticas necesarias para que este acuerdo funcione y es deber de cada ciudadano aportar a la construcción de una cultura de paz desde su contexto inmediato. Dicho contexto está constituido por la familia, la escuela, los amigos, el barrio, la vereda, el municipio, la capital, el departamento y por qué no, todo el territorio colombiano. Es así como se logra alcanzar este sueño que ha tenido Colombia por muchísimos ańos, trabajando a escala de una manera realista.

De forma mucho más técnica que los análisis precedentes, pero siguiendo la línea estatal como vía para la consecución de la paz, se encuentra el texto "Economía y paz. Colombia en un escenario de posconflicto”, de Millán y Jiménez (2017). Allí, los autores realizan un análisis comparativo entre Colombia y otros países que padecieron un conflicto armado interno prolongado, para determinar cuáles son las proyecciones económicas del país en el posconflicto. La conclusión principal del estudio es que, dado un escenario de finalización de la guerra, Colombia podrá vivir una etapa de estabilidad macroeconómica tendiente a un considerable crecimiento económico solo si se asume una acertada política fiscal, consistente en destinar los rubros de la guerra en políticas sociales, tales como investigación científica y educación, entre otros.

Por su parte, en el documento "Las políticas públicas como alternativa estructural para el desarrollo rural solidario y el posconflicto colombiano" (Herrera, 2017), se explica que las políticas públicas deben constituirse en la base de los planes y programas de todo Gobierno, y así garantizar, más allá de la teoría, la sostenibilidad, el desarrollo social rural y humano, como una alternativa de solución a los conflictos y precariedades del campo.

La falta de dichas políticas públicas de desarrollo rural en Colombia ha llevado a un marcado desaprovechamiento de la tierra y a una concentración de riquezas en amplias regiones del país. Lo anterior se establece como un problema estructural, que ha antecedido a la desigualdad social, y se ha erigido en razón principal del 
conflicto armado, como ha quedado evidenciado en las búsquedas bibliográficas. Valga decir también que la discusión sobre políticas públicas como mecanismo de empoderamiento de las comunidades en los temas que les competen es algo que escapa a todos los análisis precedentes, razón por la cual este artículo es de gran importancia y cuyo tema constituye un vacío en las exposiciones de los demás autores.

Así pues, puede verse cómo el panorama del posconflicto y los escenarios de paz resultan tan variopintos y dinámicos. Pudieron encontrarse visiones relacionadas con el tipo de justicia que se busca y su fuente de emanación (Meza, 2016; Salamanca Ospina, 2017), así como las posibilidades de desarrollo social y económico tras la firma del acuerdo (Sotelo, Castellanos y Rodríguez, 2017; Millán y Jiménez, 2017). El tema de la justicia ha sido uno de los principales objetos de discusión en torno a la firma de la paz, puesto que la sola entrega de las armas sería insuficiente para considerar el fin del conflicto; es ahí cuando emergen visiones diversas sobre cómo recibir justicia: en la perspectiva utópico-colectiva expuesta por Meza (2016), en la comunitaria e intersubjetiva de Salamanca Ospina (2017) y en la bidireccional de Marín (2017). En cualquiera de estos casos, queda clara la complejidad de la paz según su contexto social y también su necesidad en todo acuerdo, con el fin de evitar la repetición de la violencia.

Por otro lado, la cuestión de las posibilidades de desarrollo fue uno de los principales atractivos tecnocráticos del proceso de paz. Mucho se ha hablado de las ventajas comparativas que traería la cesación de las hostilidades para el sector industrial, como en la perspectiva de Millán y Jiménez (2017), pero en muchos de estos análisis se olvida que fueron causas estructurales relacionadas con el sistema económico predominante las que llevaron a la situación de guerra que aún se vive en el país. La apuesta por la educación, en la vía de Sotelo, Castellanos y Rodríguez, (2017) puede resultar lenitiva en este sentido, aunque sigue reposando en la iniciativa estatal, mientras que propuestas como la de Herrera (2017) le apuestan al empoderamiento de las comunidades a través de las políticas públicas. Lo que puede rescatarse de una pléyade de perspectivas tan variadas como opuestas es que todas apuntan a la sostenibilidad económica como garantía de paz en el posconflicto, con lo que se reconoce tácitamente que la desigualdad en esta materia fue uno de los detonantes de la guerra en el pasado. 


\section{4) Educación y posconflicto}

La conjugación de la educación y el posconflicto para el propósito de revisión de este artículo configuró la temática que más hallazgos investigativos evidenció.

En primer lugar, la Fundación para las Relaciones Internacionales y el Diálogo Exterior - FRIDE (2006), define qué es una situación de posconflicto, cuáles son las causas más recurrentes para que se desate un conflicto, cuáles son sus consecuencias y quiénes son sus principales víctimas. Este estudio tuvo en cuenta los conflictos vigentes para su fecha de expedición, incluyendo el de Colombia. Todos estos elementos posibilitan la construcción de un marco teórico sobre el tema del posconflicto y fungen como guía de búsqueda para los artículos que siguen.

Se define conflicto como:

La violencia armada en la que se enfrentan grupos de varias índoles, tales como fuerzas militares, guerrillas, grupos armados, paramilitares, comunidades religiosas o étnicas, empleando armas u otros métodos destructivos. Teóricamente los conflictos se miden por su nivel de intensidad lo que implica que un conflicto causa 25 muertes directas anuales. (FRIDE, 2006, p. 2)

Por su parte, el posconflicto sería "el período de tiempo en el cual las hostilidades del pasado se han reducido al nivel necesario para que las actividades de reintegración y rehabilitación se puedan iniciar" (FRIDE, 2006, p. 3). No obstante, el documento aclara que los conflictos suelen ser crónicos y sus secuelas pueden seguirse viendo durante décadas luego de la firma de los acuerdos de paz. Lo cual deja claro que para el caso colombiano resulta bastante difícil hablar de posconflicto, dado que aún persiste una situación de violencia, si bien significativamente menguada. Más discutible todavía resulta la implementación de los acuerdos, de cuya suerte depende en gran medida la sostenibilidad de la paz. 
En este orden de ideas, es importante resaltar aquellos estudios que hacen un análisis sobre cómo se ve el papel de la educación frente a los escenarios de paz y posconflicto en Colombia. De ellos se resaltan los siguientes:

Se aborda inicialmente el estudio "El papel de la educación en situaciones de posconflicto: estrategias y recomendaciones" (Infante, 2013), considerado desde una perspectiva cronológica como un fundamento para comprender las posteriores acciones que en Colombia se llevarían a cabo con el tratado de paz firmado en el año 2016. El estudio presenta un análisis reflexivo sobre las experiencias de posconflicto en tres países: Bosnia Herzegovina, El Salvador y Sierra Leona. A partir de la revisión histórica de los conflictos que vivieron estos países, el artículo muestra cómo estos fueron superados tras procesos de reconstrucción social, con el fin de evitar recaer en la crisis y lograr una paz duradera.

En estos procesos, Infante (2013) resalta el importante papel que desempeńó la educación como factor clave para la construcción de escenarios de protección física, psicosocial y cognitiva. De forma semejante, pero teniendo en cuenta el caso local, "Retos de la educación para el posconflicto" (Berrio y Santos, 2016) realiza una comparación sobre el modelo educativo colombiano frente a los escenarios de posconflicto de Sierra Leona, El Salvador y Bosnia Herzegovina. Con ello, desarrolla un análisis prospectivo en un escenario hipotético de ausencia de conflicto en el municipio de Buenaventura, Valle del Cauca, Colombia, y con él identifica los principales retos de la educación en el posconflicto.

Los autores concluyen que el sistema educativo colombiano requiere reformas estructurales, pues el existente obedece a características socioculturales de un contexto de conflicto armado y violencia. Por otra parte, en cuanto a la prospectiva hipotética de un escenario de conflicto a uno de no conflicto en el municipio objeto de estudio, Berrío y Santos (2016) visibilizaron el vínculo que existe entre las características de contexto social y los retos que este asume; así, los desafíos que la educación afronta en el posconflicto deben adecuarse en función del territorio y las necesidades de cada comunidad, de forma tal que el contexto devenga un facilitador para la transición de la guerra a la paz. 
En ese mismo orden de ideas, pero haciendo una mirada propiamente nacional del asunto, se presenta el artículo "El transconflicto: elementos para una utopía posible desde la educación” (Espitia y Rodríguez, 2016), el cual tuvo como propósito la elaboración de una investigación documental, orientada a buscar mediante un análisis crítico-reflexivo, estrategias recomendables que sean aplicables en Colombia, en respuesta al nuevo escenario de posconflicto desde la óptica de la educación.

Se abordan aproximaciones sobre el contexto nacional y las repercusiones que la violencia tiene sobre la población, destacando como hecho innegable el desafío que implican los rezagos de una consciencia social sobre la aceptación de la violencia como un medio de afrontamiento y cómo esto puede permear los ámbitos sociales, económicos y políticos.

Espitia y Rodríguez (2016) resaltan el papel de la educación en estos procesos de transformación social, como en Infante (2013), y plantean que el transconflicto representa oportunidades para implementar y promover la educación para la paz, argumentando que se trata de un proceso a largo plazo cuyos beneficios solo se pueden ver reflejados varias generaciones hacia el futuro, siempre y cuando se dinamicen en el presente sobre los individuos que son testigos de este proceso transitivo. La estrategia se fundamenta en un cambio de consciencia, eliminando las concepciones de violencia y familiarizándolos con las percepciones sobre la paz, con el fin de interiorizar en ellos el significado de esta como alternativa imperante de vida.

"El papel de la educación en el posconflicto" (Pérez, 2016) es un ensayo de reflexión, construido a partir de la revisión documental, en el cual se aborda la dignificación del ser humano a través de la transversalidad que humaniza la acción educativa. En ese sentido, el autor argumenta la necesidad de articular el aprendizaje social y emocional, con el propósito de lograr una estrategia de educación para la paz efectiva.

En consecuencia, el autor resalta el papel del educador como sujeto principal en el proceso educativo, en otras palabras, lo considera como el dinamizador fundamental para propiciar espacios de formación integral, favoreciendo la construcción y el reforzamiento de valores, enseñando a llevar vidas emocionalmente saludables e impulsando la convivencia pacífica y armónica (Pérez, 2016). 
"La educación como una garantía de no repetición en tiempos de negociación de la paz" (Granados, 2016) es, por su parte, un estudio que enfoca su reflexión en torno a las garantías que un proceso de paz debería otorgar a la comunidad colombiana afectada, en cuanto a la no repetición. La autora recoge los informes de las Comisiones de la Verdad, de países como Guatemala, Perú y Ecuador, y enfatiza en las medidas sobre el ámbito educativo para los Estados y la sociedad. A partir de esta reflexión concluye que las reformas al sistema educativo se deben viabilizar desde el Estado, los actores del conflicto y la sociedad en general, con el fin de contribuir en la garantía de no repetición de la violencia. También destaca que la educación en estos escenarios debe asumirse con una perspectiva que va más allá de los aspectos de cobertura y acceso, es decir, que se configure como el fundamento de la formación en actitudes y acciones que impulsen la construcción de la paz y se comprendan las implicaciones del conflicto para la no repetición.

En "Educación, conflicto y posconflicto en Colombia" (Moreno, 2017), la cuestión fundamental se centra en el reconocimiento que los actores educativos adquieren en torno al nuevo escenario de posconflicto colombiano; se hace énfasis en la ausencia de directrices claras para la acción educativa. Por lo tanto, el estudio aborda un análisis crítico de recorrido histórico, con el fin de destacar el claro reto que la escuela, y específicamente el docente, asume al abordar su papel como agente de construcción de una sociedad en transición.

Este estudio conlleva la reflexión sobre el modo como, a partir del descubrimiento crítico de una sociedad en conflicto, se pueda generar, desde el aula, la articulación coherente entre el conocimiento planteado por los currículos y las esperanzas de una sociedad capacitada para vivir en el posconflicto. Esta coyuntura puede reforzarse por el empoderamiento de los docentes y sus procesos formativos e investigativos, pues "un docente como intelectual debe edificar herramientas para interpelar al poder, lo que redundará en su participación en la construcción de políticas públicas como un actor destacado" (Moreno, 2017, p. 140).

"Pedagogía, educación y paz en escenarios de posconflicto e inclusión social" (Valencia, Corredor, Jiménez, De los Ríos y Salcedo, 2016) expone el tema de la educación y la cualificación docente en torno a los escenarios de posconflicto. Se 
desarrolla una reflexión sobre un proceso formativo de cara a las necesidades reales del momento histórico y a las trasformaciones que debe experimentar el sujeto y la sociedad desde la perspectiva del tránsito y la mediación de pedagogías didácticas que interioricen, además de conocimientos, consciencia social y convivencia. En ese sentido, los autores resaltan la necesidad de generar procesos que permitan la correspondencia entre el currículo y la pedagogía, según las características y los factores de contexto.

"Revisión de la literatura de la relación entre conflicto armado y educación en Colombia" (Palacios, 2017) es el resultado de un proceso investigativo, de donde se deriva este artículo construido a través de la revisión bibliográfica empírica, relacional al conflicto armado y la educación en Colombia. Este estudio desarrolla una descripción de los enfoques identificados en materia académica en cuanto a la relación entre factores asociados (la cobertura educativa, la deserción escolar y la calidad educativa) y los contextos de violencia generados por el conflicto armado. Se destaca cómo esto redunda negativamente en las políticas sociales, no solo en la formulación, sino más preocupante aún, en la dificultad para su aplicación.

Los rezagos de la violencia impiden el desarrollo del sistema educativo nacional, pues las agresiones han sido devastadoras y han generado un sentido de desconfianza. Como hecho dado, la imposibilidad de acceder a una educación de calidad, a causa del conflicto armado, significó la perpetuación de la pobreza y la victimización de la población colombiana. Desde esta perspectiva, la autora concluye que estos factores profundizaron la vulnerabilidad de las víctimas; por ello, el logro de una paz duradera y estable se dificulta si no se fundamenta en políticas públicas accesibles y reales (Palacios, 2017).

"Colombia: de la educación en emergencia hacia una educación para el posconflicto y la paz" (Pérez, 2015) es un artículo producto de una investigación aplicada en el que se aborda la seria problemática que la educación tuvo que afrontar en tiempos de violencia, derivada de las ineficaces y escasas políticas públicas destinadas a atenuar los flagelos de la guerra en niños y adolescentes. Posteriormente, a partir de las negociaciones en La Habana, surge el reto de educar para el posconflicto, 
la reconciliación y la paz. A partir de ambos fenómenos, el autor intenta describir la educación en emergencia en contextos de conflicto armado, los escenarios que se desprenden a partir del proceso de justicia transicional y la comprensión del posconflicto, y los retos de la educación en la construcción de paz.

En concordancia con otros estudios relacionados, este desarrolla los desafíos que enfrenta la escuela en un proceso de posconflicto; a partir de ello consigue distinguir la importancia de fortalecer la formación en derechos humanos y la formación para el desarrollo rural, siendo esta último tan necesaria como la primera, ya que se habla de la porción de la población más vulnerable frente a todas las modalidades de hechos violentos que recrudecieron el conflicto armado a través de los años.

"El papel que juega la educación secundaria en el conflicto y en el postconflicto colombiano" (Rivas, 2015), es un estudio que se orienta a la argumentación dialógica, producto de una revisión documental, con la cual se buscó comprender la situación de la educación secundaria en tiempos de conflicto armado y en los nuevos escenarios de paz del posconflicto. El autor llega a la conclusión de que "la educación puede ser un medio para poder alcanzar la paz, pero también puede llegar a ser un detonante para comenzar un conflicto armado" (Rivas, 2015, p. 4), explicando la importancia de la educación en la estructura social, pues al constituirse como derecho inalienable de los individuos, esta se debe garantizar a todos ellos y en las mejores condiciones para promover calidad de vida y un tejido social estable y en paz. De forma opuesta, la incapacidad del Estado y de la sociedad misma de garantizar la educación con calidad promueve la perpetuación de las brechas de desigualdad y la inevitable inestabilidad social, conduciendo a la detonación de hechos violentos.

Por ello, Rivas (2015) destaca la educación en un escenario de posconflicto como un ámbito que requiere de esfuerzos conjuntos para asumir los múltiples retos que la desafían, en un momento en el cual la educación secundaria vive precarias condiciones de reforma. Si bien la educación se configura como la clave de superación del conflicto y la adopción de la paz, no se puede desconocer que el reconocimiento de la realidad y el contexto son fundamento para lograr aportes significativos al fenómeno de posconflicto. 
Los autores del estudio titulado "La educación y la pedagogía en el escenario del posconflicto en Colombia” (Tovar y Vélez, 2017), a través de la recopilación teórica sobre la educación y las concepciones que giran en torno a ella en un escenario de posconflicto, dilucidan los retos sociales, no solo de la educación como sistema, sino además de la pedagogía como elemento movilizador de la misma y destacan la importancia del papel del educador en estos procesos como actor influyente y no como ente aislado, transmisor de conceptos. Abordando dichos postulados, los autores consideran que la formación del docente en un escenario de posconflicto depende en gran medida de los elementos pedagógicos que eviten la reproducción de discursos que propicien y alimenten la violencia.

Ahora bien, teniendo en cuenta estudios que además de la revisión documental, desarrollaron ejercicios investigativos que implicaron el acercamiento a la realidad de las comunidades, se destaca el denominado "La escuela en escenarios de conflicto: daños y desafíos" (Osorio, 2016), el cual realiza una investigación de corte cualitativo, mediada por un estudio de caso, en una institución educativa de la zona rural de un municipio afectado por la violencia, y que vive de cerca el momento de transición que representa el posconflicto.

Osorio (2016) identifica que la efectividad de los procesos de formación en escenarios de posconflicto depende de la reflexión y el análisis crítico de los estudiantes, docentes y demás integrantes de la comunidad educativa, sobre la memoria histórica y la reconciliación, para construir una sociedad distinta.

Así pues, el autor llega a concluir que las instituciones educativas deben adelantar tareas como la visibilización de las víctimas como ciudadanos, la participación en la construcción de narrativas de la memoria y la cimentación de una cultura para la paz, la reconciliación, la democracia y el respeto por los derechos humanos.

Por otra parte, en los hallazgos de la revisión investigativa, se encontraron estudios que han intentado reflexionar, comprender y proponer aspectos fundamentales que conjugan la pedagogía educativa con el posconflicto y la formación para la paz. La pedagogía es, desde esta mirada, la herramienta fundamental de la praxis educativa, que se dinamiza a través del educador como actor de transformación docente, como 
el sujeto político que además de cumplir con el ejercicio de impartir conocimientos, profundiza en la formación emocional, de valores y convivencia de sus estudiantes.

Sin embargo, para el cumplimiento de su compromiso social, el docente requiere asumir, desde su voluntad individual y profesional, los desafíos que el posconflicto requiere, tales como la formación para la paz del educador, la pedagogía social, la adaptación de las condiciones de la escuela y la realidad de las comunidades.

"La escuela en ecologías violentas: entre las políticas y la pedagogía de la memoria", desarrollado por los autores Vélez, Ortega y Merchán (2017), aborda la pedagogía de la memoria, de manera que se asuman éticamente las memorias del pasado reciente sobre el sujeto y las ecologías de la violencia, con la finalidad de conseguir un renacer del individuo como un sujeto político movilizador de la transformación de su entorno.

En un sentido afín, el estudio "La pedagogía social como condición de posibilidad en escenarios de posconflicto: construcción desde la praxis social”, realizado por Álvarez (2016), asume la pedagogía como la herramienta de transformación en entornos reales, que es próxima al sujeto y a su comunidad. Por medio de la pedagogía social se promueve la formación en un momento de justicia transicional. En este estudio se plantea, desde la comprensión conceptual, la pedagogía social como el discurso de la praxis de la educación en la construcción de comunidad para la paz, de manera que se reconoce la misión práctica de formación e interiorización de valores y características que distinguen a una sociedad justa, y se rompen los paradigmas de una consciencia colectiva producto de escenarios de violencia.

De un modo complementario al estudio referenciado anteriormente, se aborda el artículo denominado "La pedagogía social en el posconflicto colombiano" (Tabla, 2015), que además de postular la pedagogía social como la praxis educativa para la transformación social en un escenario de posconflicto, propende por la formación de ciudadanos críticos que movilicen el cambio en un marco interinstitucional, aludiendo a la importancia de la pedagogía como hecho dado que va más allá de las reformas curriculares y las cátedras para la paz. Según este autor, si bien la reflexión 
es importante, los verdaderos cambios se hacen en la praxis, o en otras palabras, se promueven a través de la pedagogía y el accionar docente.

Finalmente, se encontraron dos estudios que bajo los preceptos teóricos de la educación y sus desafíos en el posconflicto, aunados a la concepción de la pedagogía social en el aula, plantean propuestas pedagógicas aplicadas a grupos en procesos de formación en el afrontamiento de los nuevos escenarios de paz y posconflicto. A continuación se hace una breve descripción de estos:

"La fábula como mediación pedagógica para la construcción de cultura de paz y perdón en el posconflicto en básica primaria del Colegio Nuevo Chile I.E.D.” (Herrera y Ronderos, 2017), es un estudio que brinda elementos que pretenden enriquecer la práctica docente, creando e implementando mediaciones pedagógicas que fomenten la cultura de paz y perdón en las instituciones educativas de posconflicto. El trabajo investigativo permitió concluir que, si bien los docentes tienen un grado de disposición e interés por aportar en la formación de la paz, también evidencian situaciones que desde la condición humana y del ejercicio profesional se deben trabajar a partir de la contextualización y la formación docente, con el objetivo de mejorar su desempeño en el aula en el marco del posconflicto. Sin embargo, promover este tipo de estrategias incentiva la transformación de la dinámica en el aula, acercando más a los actores al escenario de paz y permitiéndoles disminuir la brecha entre lo teórico y lo práctico.

"Pedagogías para la paz: una propuesta de educación popular por medio del arte, para la formación de los niños y niñas en la paz” (Bejarano, Londoño y Villa, 2016), es un estudio en el que se adelanta una propuesta de praxis educativa a través de las expresiones artísticas de los estudiantes de la mano con el docente. Su fin es promover enseñanzas significativas sobre las huellas que ha dejado el conflicto armado en Colombia, abordando la reconciliación, el rescate de la memoria para la no repetición y la adopción de las alternativas de convivencia para interactuar en contextos sociales y construir una memoria colectiva fundamentada en el concepto de paz; por ello la población objeto de estudio es infantil. Se resalta la importancia del comienzo de una pedagogía social movilizada por el arte, con las generaciones nacientes, en un momento de posconflicto. 
En una línea similar, aunque mucho más específica, la tesis de Arias (2010) titulada "Situación del derecho a la educación, en los componentes de aceptabilidad y adaptabilidad, de niñas y niños víctimas del conflicto armado, en instituciones educativas públicas de Medellín”, hace una mirada de corte crítico en una de las regiones más afectadas por el conflicto armado interno en Colombia. Desde una apuesta hermenéutica, el autor destaca los contextos de desarraigo a los que han sido sometidos los niños víctimas del conflicto, y cómo sobre ellos pesa una revictimización, esta vez no por parte de los actores armados, sino de la institucionalidad y de la comunidad misma, al ser en ocasiones excluidos del sistema educativo, tratados con inequidad o asimetría, o rechazados de facto por sus compañeros y los padres de familia de los demás niños. Se destacan los mecanismos jurídicos que existen para atender y superar estos casos, aunque se resalta su insuficiencia, por lo que se hace el llamado a un tipo de trabajo social con las comunidades, ya que la reconciliación debe ser no solamente entendida entre el Estado y los alzados en armas, sino también entre la diversidad de comunidades que padecieron la guerra, por acción, omisión o victimización directa.

En suma, la presentación de artículos e informes de investigación precedentes arroja varios puntos interesantes para tener en cuenta: en primer lugar, el interés que el tema de la educación y el posconflicto ha tenido en la academia es una muestra de la preocupación por el componente educativo en escenarios de guerra, prueba palmaria de la imbricación entre ambos fenómenos, pero también, evidencia de la concepción de la educación como la ruta más segura hacia el progreso y la superación de la violencia. En segundo lugar, la cantidad de artículos encontrados en este apartado es un indicador de los avances que desde la academia se han hecho al respecto, en contraste con los demás componentes que integran esta revisión. En tercer lugar, la semejanza de los abordajes en términos conceptuales y temáticos, más allá de las aristas metodológicas, puede ser tanto una muestra de coherencia en lo que respecta a la identificación de los temas importantes en relación con el posconflicto, como una carencia de abordajes críticos que problematicen el fenómeno de la educación en un escenario de no guerra. Por último, la lectura de estos documentos deja una sensación de tranquilidad y esperanza, pero al mismo tiempo de sospecha y escepticismo, toda vez que no resulta muy acorde tanta eficiencia y buena gestión con los antecedentes del país, particularmente en materia educativa y en medio de la polarización política que en torno a la paz se vive hoy en día. 


\section{5) Docentes en escenarios de posconflicto}

Este es un momento crucial para el país y principalmente para quienes tienen la responsabilidad social de la formación de los sujetos; es decir, es tarea de los docentes estar al día con los acontecimientos del país y a su vez con las normativas que los rigen.

Al analizar esta realidad, Duque y Lasso (2016), en su artículo de investigación denominado "Autopercepción de saberes y prácticas sobre educación y desplazamiento forzado en docentes de Cali, Colombia”, se encuentran con el siguiente hallazgo: en el ejercicio de visibilizar el alcance que tiene la política pública en las prácticas y dominios de saber de los docentes, se revela una situación supremamente problemática relacionada con el desconocimiento de las directrices y los programas estatales por parte de los docentes, situación que refleja lugares de carencias, a su vez que permite reconocer escenarios de posibilidad.

Es allí cuando se debe fortalecer y capacitar a los docentes, tanto desde el conocimiento de la ley como del diseño e implementación de diversas estrategias metodológicas, viéndolo como un escenario de posibilidad y pertinencia para la reparación de aquellas víctimas del conflicto que regresan a las aulas, especialmente en aquellas zonas rurales que ameritan ser fortalecidas en todas sus dimensiones. Como lo dicen Duque y Lasso (2016), la responsabilidad de este acompańamiento involucra tanto la dimensión gubernamental en la destinación de recursos y esfuerzo continuo en la formación docente, como responsabilidades compartidas, en este caso con la academia como un acompañante de procesos formativos.

Montero (1991), con respecto al lugar de la psicología política latinoamericana, refiere su rol situado en lo que respecta a la denuncia y la transformación. Es un asunto destacado y perseguido como uno de los objetivos de la educación el que sea de carácter emancipadora y que busque ser transformadora. El docente debe ejercer ciertos roles que hoy están marcados en la sociedad, y por múltiples problemáticas a las que se enfrenta la educación, muchas veces este se ve coartado en su accionar pedagógico o simplemente se entra en un estado de adormecimiento por miedo al cambio. Pero esto debe transformarse. Como lo manifiesta Hermida (2016) en su tesis "Desafíos de un docente del área artística en la Institución Educativa Aquilino 
Bedoya en el posacuerdo armado", debe haber una disposición hacia el cambio conductual del maestro del área artística y desde lo procedimental, ya que uno de sus roles fundamentales es implementar estrategias que promuevan la dialogicidad dentro del aula de clase. Aunque lo anterior no es responsabilidad exclusiva de los maestros de educación artística sino de todos aquellos que ejercen dicha profesión.

Tanto Hermida (2016) como Duque y Lasso (2016) muestran realidades diferentes acerca del rol del docente en el posconflicto, pero estos pueden complementarse si se tiene en cuenta la complejidad del papel desempeñado por los maestros como referentes sociales de primer orden y ser los directamente encargados de los procesos de socialización. En un escenario de posconflicto, son los docentes los que deben hacer un significativo aporte a la construcción de paz sostenible, y para ello deben tener conocimiento de su posición en la historia -en la perspectiva de Duque y Lasso (2016) - así como una actitud creativa e innovadora de su quehacer cotidiano -en el planteamiento de Hermida (2016)-. Ambos escenarios atravesados por el necesario acompańamiento estatal.

Precisamente en lo que respecta al papel del Estado en el apoyo a la cualificación docente de cara al posconflicto, se encuentra el texto de Osorio (2015) titulado "La educación como pilar del posconflicto". En él, el autor hace un análisis crítico de la situación de la educación en el país y particularmente de las recientes propuestas emanadas del Ministerio de Educación para mejorar su calidad, apelando a la importación de modelos foráneos que poco o nada tienen que ver con la idiosincrasia nacional y sus formas culturales. Realiza una problematización de este fenómeno en el escenario del posconflicto, en especial del rol jugado por un docente transido de carencias formativas, actitudinales y pecuniarias, aspecto no explorado en profundidad por los autores precedentemente expuestos en este apartado. Reclama del Estado atención prioritaria y suficiente para que el docente pueda encarnar los retos que demanda el posconflicto, y no duda en mostrar a la educación como el nodo del mismo:

Este desafío demanda que la educación se convierta en eje del posconflicto. Para lograrlo, es preciso que la estrategia de disponibilidad se acompañe de 
una Política de Pertinencia Educativa y de desarrollo profesional docente, como eje de la política nacional de educación. (Osorio, 2015, pp. 16-17).

No cabe duda de que los tres textos aquí mencionados asumen la educación como elemento central del sostenimiento de la paz y al docente como el actor que encarna dicha responsabilidad. También queda claro que existe convergencia entre los análisis en lo que respecta a las insuficiencias de toda índole (económicas, académicas, físicas, actitudinales, etc.) que los docentes tienen que soportar para desempeñar su labor, situación agravada por un momento histórico en el que la garantía de mantenimiento de la paz para las nuevas generaciones está, hasta cierto punto, en sus manos. Por otro lado, también está fincada la esperanza del futuro del país, para estos autores, en el ejercicio docente como eje fundamental del acto educativo.

\section{6) Responsabilidades de la educación superior en el posconflicto}

La educación superior en Colombia ha estado supeditada a las políticas gubernamentales de turno. Esta se ha visto afectada, olvidada y mercantilizada por las propuestas del Banco Mundial, las cuales han sido el blanco de aquellos modelos elitistas en los que priman los intereses de unos pequeños grupos que atienden a las lógicas del mercado actual.

Yepes (2016), en el libro resultado de su investigación denominado "Retos y dilemas de la educación superior pública en Colombia", llega a la conclusión de que la educación superior en Colombia ha sido objeto de importantísimos procesos de transformación, especialmente en cuanto a los cambios acaecidos en el último mandato del expresidente Santos, quien en virtud de la movilización social y política del estudiantado colombiano ha asumido el reto de diseñar una política pública para la educación superior en el escenario del posconflicto y con un horizonte al año 2034. Se espera que la participación comprometida de todos los actores interesados en la materia logre presionar lo suficiente para que se materialice una de las mejores políticas públicas sectoriales que jamás se hayan construido en Colombia: la de la educación superior para los próximos veinte años. 
Si se habla de políticas públicas, esto no siempre quiere decir que estas dependan exclusivamente del Gobierno; también se han dado acercamientos desde los dos planes decenales de educación. Pero esto es solo un modesto intento por sacar la educación superior adelante, disminuyendo aquellas brechas de accesibilidad, equidad, pertinencia y beneficio social, entre otras.

Por su parte, Baquero y Ariza (2014) en su artículo "Educación, paz y posconflicto: oportunidades desde la educación superior", manifiestan una de las opciones que tiene la universidad en Colombia la cual consiste en reducir la brecha que hay entre Estado, familia y educación. En un programa para la paz, la educación superior evidencia la necesidad de articular sus funciones educacionales con el Estado y su liderazgo gubernamental. Es imposible que la universidad actúe de manera secuencial, coherente y trascendental al verse limitada ante un Gobierno indiferente que desdeña lo que los estudiantes universitarios puedan realizar desde la academia. En cuanto a la familia, también se debe reconocer su aporte para la paz, sus principios éticos y morales son de gran importancia para una generación de jóvenes reconciliados, pues la educación se inicia en casa. Lo anterior es una visión interesante que sin embargo desconoce los acertados planteamientos de Yepes (2016) en relación con la crisis de la educación superior pública, principal abanderada de los procesos de transformación social en el marco del posconflicto.

En relación con el Acuerdo por lo Superior 2034 (Consejo Nacional de Educación Superior - CESU, 2013), este se fundamentaría principalmente en el quehacer diario de las aulas universitarias. De allí surge un sujeto importante a la hora de mediar unos valores y conocimientos para la paz: el docente universitario, cuyo rol en la sociedad es contundente y constante en la construcción de universidades para la paz. Su mediación consiste en lograr motivar y formar estudiantes sociocríticos e investigativos, puesto que este aspecto tiene un rol central en el proceso formativo de los jóvenes universitarios. Así, valiéndose de herramientas reconocidas o no, el docente debe enfrentarse a una realidad cultural y social estrecha, ya que no se ofrecen infraestructuras acordes con las perspectivas para una educación en paz, y existen unas políticas económicas muy limitadas para lo que se tiene planeado. Valga decir que este documento fue producto de importantes académicos (Yepes entre ellos) en conjunto con las expresiones profesorales del movimiento universitario que 
lucha por una educación superior pública y de calidad al servicio especialmente de los sectores menos favorecidos de la sociedad.

Pachón, Gómez y Méndez (2017) en el artículo titulado "Colombia: educación superior y posconflicto. Proceso de reconstrucción de tejido social basado en el posconflicto", aseguran que los procesos de reconstrucción del tejido social y las reformas al sistema de educación resultan un elemento fundamental, en la medida en que las estrategias para reducir el riesgo de conflicto o su profundización deberán cimentarse en el desarrollo de competencias ciudadanas -emocionales, cognitivas y comunicativas- que permitan abordar y entender la condición humana a partir de la otredad, como parte constitutiva de la existencia de lo social. Más cercanos a la mirada de Baquero y Ariza (2014), la apuesta aquí es mucho más académica y tecnocrática que política, como ocurre con las miradas de Yepes (2016).

En un sentido completamente diferente, y siguiendo a Carrillo (2013) en relación con la reinserción de los exmilitantes de la insurgencia a la vida civil, debe tenerse en cuenta que la transformación del sistema educativo en escenarios de inclusión implica el establecimiento de procesos académicos flexibles, con el fin de generar acciones que no juzguen a los excombatientes, permitiéndoles retomar su proceso educativo sin temor a ser estigmatizados.

Sin embargo, como lo plantea Carrillo (2013), en el caso colombiano esto debe ir rigurosamente articulado con la Ley de Víctimas como parte integral del resarcimiento del dolor, el perdón y la reconciliación, con el propósito de establecer mancomunadamente un vínculo holístico entre víctimas y victimarios, en función de la construcción de una paz duradera. La de Carrillo es una exposición de trascendental importancia, dado que el tema de la reinserción siempre resulta polémico y poco explorado por los temores que suscita, como lo confirma la nula mención por parte de los demás autores, incluso aquellos pertenecientes a los movimientos universitarios.

En un abordaje mucho más particular, contrastante con las exposiciones más generales de los autores precedentes, pero que implica la discusión de algunos de los pilares de la idea de universidad, Carrizosa (2018) hace una exposición de los retos 
que para las escuelas de medicina tendrá el posconflicto, no solo desde lo disciplinar sino también desde lo curricular en los claustros universitarios. Introduce el tema de los derechos humanos para problematizar una dinámica que durante las peores épocas del conflicto azotó a cientos de personas: la negación de servicios a los alzados en armas o a quienes estuvieran bajo sospecha de serlo. El autor dice que la labor del médico no puede tener limitantes políticas que impidan el cumplimiento de su misión social.

Adicionalmente, menciona el concepto de autonomía universitaria para marcar una distancia con respecto a la institucionalidad estatal, dejando claro que no se puede ir a la orilla contraria y sacrificar el desarrollo universitario interno en aras de los intereses gubernamentales de turno, aun bajo la excusa de la paz; por encima de esto, el desarrollo de los currículos universitarios debe responder a la reflexión académica y no a las coyunturas políticas. Finalmente, hace un llamado para que la necesaria modificación de los currículos de medicina pase por una discusión amplia y democrática, en la que también tengan participación los excombatientes recién integrados a la vida civil.

$\mathrm{Al}$ analizar lo anteriormente postulado por los autores, se hace latente la inmensa necesidad de buscar un cambio, una transformación de la realidad actual del país y explorar en la educación el sentido y el norte que necesita la sociedad colombiana. La educación es el arma más poderosa con que cuentan los sujetos para transformarse a sí mismos y aquello que los rodea, siendo capaces de hacer cosas nuevas.

Además, lo planteado por los autores va en relación con la postura de sujeto político que se desea alcanzar desde el rol del docente en la educación rural en los escenarios de paz y posconflicto, pensando en la reparación de víctimas que llegarán a todos los sectores y niveles de la educación, es decir, desde la primaria hasta la educación superior. La pretensión es que desde cualquiera de estos niveles se cree consciencia para que ellos tengan un cambio de vida y se sientan a gusto en cualquier espacio; no que se sientan con un trato especial por la condición de víctimas o victimarios, sino que sean reconocidos como sujetos libres, cargados de historias que sean la base de su memoria y la memoria del país, para aportar a los demás y construir desde allí una paz estable y duradera que permita la reconstrucción de dicho tejido social. 


\section{7) Educación rural y posconflicto}

Esta es una temática muy poco explorada desde la investigación educativa, ya que al conjugar aquellas categorías, los estudios han sido pocos. Teniendo en cuenta esto, González y Varela (2017), en su estudio "Aportes a la formación de un docente rural para el posconflicto", hacen un despliegue interesante acerca de los contextos, la relevancia del reconocimiento y posterior comprensión de acontecimientos históricos en los procesos de formación de docentes rurales, así como de los estudiantes inmersos en contextos afectados por la violencia. A lo largo de este proyecto han encontrado 12 aportes para la formación de un docente rural para el posconflicto:

1. Resaltar la importancia del reconocimiento de la historia de regiones que vivieron el conflicto como San Vicente del Caguán; 2. la afirmación del docente como sujeto político para reconocerse y reconocer al otro; 3. abordar la existencia de una hibridación social entendiendo las realidades del otro para evitar la violencia; 4. saber sacar provecho de la mezcla del saber del campo con lo urbano desde la interdisciplinariedad para la hibridación geográfica que permita hacer del proceso de enseñanza algo significativo; 5. la necesidad de apropiar en la formación inicial los proyectos educativos que el MEN ha implementado para las escuelas rurales; 6 . para la formación permanente se hace necesaria la sistematización de experiencias o prácticas pedagógicas; 7. la apertura de espacios ilimitados que permitan la integración de la comunidad local con la comunidad educativa para la construcción de la paz; 8. hace referencia a los valores lasallistas que permiten al docente formar sujetos de paz; 9. contemplar la emocionalidad del docente hacia las realidades conflictivas que han vivido sus estudiantes; 10. la comprensión del aula multigrado para maximizar sus cualidades; 11. la comprensión de los recursos y su adaptabilidad en el aula rural, tener en cuenta los saberes previos de los estudiantes para complementar dichos conocimientos y, 12. la importancia de abrir espacios para realizar prácticas pedagógicas en zonas rurales.

En un análisis más estructural, el Centro Noruego para la Resolución de Conflictos - NOREF, plantea que la inversión en educación es la garantía para la construcción de una verdadera paz con justicia social, tal como quedó plasmado en el acuerdo final entre el Gobierno nacional y las Farc-EP. También muestra con cifras 
la magnitud de la exclusión que los niños de las zonas rurales han padecido por cuenta del conflicto, y cómo esto los ha alejado de las aulas de clase. La exposición institucional sobre la educación rural pasa por el análisis sobre el abandono estatal de estas regiones y su población, la cual ha vivido atrapada en medio del fragor de la lucha armada, victimizada por todos los actores beligerantes y discriminada por sus pares en las ciudades o pueblos a donde llegan en condición de desplazamiento. Una de las tesis más interesantes del documento es la que muestra una correlación entre los bajos índices de escolaridad y la integración de filas en los grupos armados, lo cual es indicador de la capacidad reproductiva de la violencia en contextos de abandono estatal y carencias educativas. Por último, hace un pronóstico no muy halagüeño del futuro de la educación rural en el posconflicto, a la luz de las más recientes declaraciones de las entidades vinculadas con el tema, asegurando que "de las entrevistas realizadas no se deduce que las instituciones educativas se estén planteando el posconflicto como una oportunidad para poner en marcha reformas ambiciosas e inversión en el ámbito de la educación rural” (NOREF, 2016, p. 14).

\section{Conclusiones}

A partir del recorrido bibliográfico desarrollado en el presente artículo, se permite vislumbrar la novedad de este estudio en construcción, el cual radica en que el país aún comienza un camino hacia la construcción de escenarios de paz, en el que los actores son el principal elemento para alcanzar los objetivos fundamentales de desarrollo social y humano. De ahí que la investigación implique un referente teórico y orientador en las nuevas propuestas que deben surgir desde el docente, mediadas por las herramientas que las políticas públicas ofrecen, en tanto estas se logren aplicar a los contextos rurales.

En atención a todo lo anteriormente expuesto, es posible recurrir a aquello en que muchos teóricos, críticos y demás expertos en temáticas de guerra, resolución de conflictos y reparación de derechos, concuerdan: la premisa de que una de las claves para superar la violencia y el conflicto es la educación, pues un pueblo educado tiene más posibilidades de mediar las brechas de la pobreza y la desigualdad, para desarrollarse de forma integral y sostenible; así entonces, por una parte el Estado es 
el que debe asumirlo desde las políticas públicas y por otra, la sociedad desde la vida en sus contextos particulares.

En todo este proceso, es posible identificar en la comunidad ciertos sujetos que adquieren un alto grado de importancia desde el rol como agentes políticos que desempeñan en la sociedad, tales como los docentes, quienes se configuran como transformadores sociales en todos los niveles educativos. Desde su pedagogía en el aula, ellos son capaces de movilizar la construcción de la paz individualmente en sus estudiantes, aportando a la reparación de los escenarios del posconflicto a través de la formación interdisciplinar basada en valores como el respeto por el otro, la reconciliación y la participación; lo cual, se puede traducir en el tiempo en una minimización del riesgo de recaer en la reconfiguración de nuevos estados de violencia en los contextos próximos.

\section{REFERENCIAS}

Álvarez, M. (2016). La pedagogía social como condición de posibilidad en escenarios de posconflicto: construcción desde la praxis social. Boletín Redipe, 5(5), 33-42. Recuperado de https://dialnet.unirioja.es/servlet/articulo?codigo=6064412

Arévalo, J. (2014). Construcción de paz y un nuevo modelo de construcción de Estado: una lectura de los dos primeros acuerdos de La Habana. Revista de Economía Institucional, 16(30), 131-169. Recuperado de http://www.redalyc. org/html/419/41931001007/

Arias, E. (2010). Situación del derecho a la educación, en los componentes de aceptabilidad y adaptabilidad, de niñas y niños victimas del conflicto armado, en instituciones educativas públicas de Medellin (tesis de maestría). Universidad de San Buenaventura, Medellín, Colombia. Recuperado de https://bibliotecadigital.usb. edu.co/bitstream/10819/512/1/Situacion_Derecho_Educacion_Arias_2010.pdf 
Baquero Rodríguez, M., y Ariza Landínez, P. (2014). Educación, paz y posconflicto: oportunidades desde la educación superior. Revista de la Universidad de La Salle, 65(4), 115-134. Recuperado de https://ciencia.lasalle.edu.co/cgi/viewcontent. cgi?article $=1428 \&$ context $=$ ruls

Barreto Henríquez, M. (2015). El programa de desarrollo y paz del Magdalena Medio: ¿un modelo de construcción de paz para el postconflicto en Colombia? Papel Politico, 20(2), 461-479. Recuperado de http://www.redalyc.org/comocitar. oa?id=77745626007

Bejarano, N., Londoño, J., y Villa, P. (2016). Pedagogías para la paz: una propuesta de educación popular por medio del arte, para la formación de los niños y niñas en la paz (tesis de grado). Universidad de Antioquia, Medellín, Colombia. Recuperado de http://ayura.udea.edu.co:8080/jspui/bitstream/123456789/2187/1/CA0183_ norman_johana_paulina_pedagogiapaz.pdf

Berardi, A. (2015). La crisis de la sociedad y la construcción del sujeto político desde la perspectiva de Durkheim, Tönnies y Weber. Entramados y perspectivas, 5(5), 179-201. Recuperado de http://publicaciones.sociales.uba.ar/index.php/ entramadosyperspectivas/article/view/1490/1363

Bergmann, A. (2011). ¡Otra justicia es posible! Justicia restaurativa, comunitaria y social en El Salvador. San Salvador, El Salvador: Quetzalcoatl.

Berrío Nieto, D. M., y Santos Rodríguez, M. A. (2016). Retos de la educación para el posconflicto (tesis de posgrado). Universidad Nacional Abierta y a Distancia, Bogotá D. C., Colombia. Recuperado de https://repository.unad.edu.co/ handle/10596/13917

Bustos, A. (2008). Docentes en escuela rural. Análisis de su formación y sus actitudes a través de un estudio cuantitativo en Andalucía. Revista de Investigación Educativa, 26(2), 485-519. Recuperado de http://www.redalyc.org/ pdf/2833/283321909012.pdf 
Carrillo, J. F. (2013). Informe parcial de investigación acerca de medidas tomadas por distintos paises para la incorporación de excombatientes a la vida civil por medio de iniciativas educativas especificas y normas expedidas para lograrlo. Bogotá D. C., Colombia: Ministerio de Educación Nacional.

Carrizosa, J. (2018). La educación superior en el escenario del posconflicto: reflexión desde la Facultad de Medicina. Medellín, Colombia: Universidad de Antioquia. Recuperado de https://bit.ly/312hM9H

Cea D’Ancona, M. (1996). Metodología cuantitativa. Estrategias y técnicas de investigación social. Madrid, España: Síntesis.

Centro Noruego para la Resolución de Conflictos - NOREF. (2016). El verdadero fin del conflicto armado: jóvenes vulnerables, educación rural y construcción de la paz en Colombia. Recuperado de https:/www.nrc.no/globalassets/pdf/reports/ noref_report_nrc_educacion_colombia_2016.pdf

Consejo Nacional de Educación Superior - CESU. (2013). Acuerdo por lo Superior 2034. Propuesta de política pública para la excelencia de la educación superior en Colombia en el escenario de la paz. Bogotá D. C., Colombia: CESU. Recuperado de https://www.dialogoeducacionsuperior.edu.co/1750/articles-321515_recurso_1. pdf

Cossio, J. A. (2014). Pedagogía y calidad de la educación: una mirada a la formación del maestro rural. Sophia, 10(1), 14-23.

Devia, C., Ortega, D., y Magallanes, M. (2014). Violencia luego de la paz: escenarios de posconflicto en Centroamérica. Revista Republicana, 17(2), 119-148. Recuperado de http://ojs.urepublicana.edu.co/index.php/revistarepublicana/ article/view/14/13 
Duque Vargas, N. H., y Lasso Toro, P. (2016). Autopercepción de saberes y prácticas sobre educación y desplazamiento forzado en docentes de Cali, Colombia. Revista Colombiana de Psicología, 25(1), 155-173. Recuperado de http://www.scielo.org. $\mathrm{co} / \mathrm{pdf} / \mathrm{rcps} / \mathrm{v} 25 \mathrm{n} 1 / \mathrm{v} 25 \mathrm{n} 1 \mathrm{a} 11 . \mathrm{pdf}$

Durkheim, E. (1997). La educación moral. Buenos Aires, Argentina: Losada.

Espitia, U., y Rodríguez, E. (2016). El transconflicto: elementos para una utopía posible desde la educación. Panorama, 10(18), 94-100. Recuperado de http:// journal.poligran.edu.co/index.php/panorama/article/view/825/632

Fundación para las Relaciones Internacionales y el Diálogo Exterior - FRIDE. (2006). El posconflicto bajo el prisma de las víctimas. Recuperado de https:// docplayer.es/12640260-El-posconflicto-bajo-el-prisma-de-las-victimas.html

González, L., y Varela, P. (2017). Aportes a la formación de un docente rural para el posconflicto (tesis de grado). Universidad de La Salle, Bogotá D. C., Colombia. Recuperado de http://repository.lasalle.edu.co/bitstream/ handle/10185/21432/26122053_2017.pdf?sequence=1\&isAllowed=y

Granados, D. (2016). La educación como una garantía de no repetición en tiempos de negociación de la paz. Trabajo Social, 18, 57-74. Recuperado de https:// search.proquest.com/docview/1802640849/fulltextPDF/AC298789D2644A0P $\mathrm{Q} / 13$ ?accountid $=36216$

Hermida, C. M. (2016). Desafios de un docente del área artística en la Institución Educativa Aquilino Bedoya en el posacuerdo armado (tesis de maestría). Universidad Católica de Pereira, Colombia. Recuperado de http://repositorio.ucp.edu.co/ handle/10785/4038

Herrera Guzmán, A. (2017). Las políticas públicas como alternativa estructural para el desarrollo rural solidario y el posconflicto colombiano. Revista Universidad de La 
Salle, 74(4), 1-30. Recuperado de https://ciencia.lasalle.edu.co/cgi/viewcontent. cgi?article $=2156 \&$ context $=$ ruls

Herrera, W., y Ronderos, A. (2017). La fábula como mediación pedagógica para la construcción de cultura de paz y perdón en el postconflicto en básica primaria del Colegio Nuevo Chile I.E.D. (tesis de maestría). Universidad de La Salle, Bogotá D. C., Colombia. Recuperado de http://repository.lasalle.edu.co/bitstream/ handle/10185/21666/85152246_2017.pdf?sequence=1\&isAllowed=y

Infante, A. (2013). El papel de la educación en situaciones de posconflicto: estrategias y recomendaciones. Hallazgos, 11(21), 223-245. Recuperado de http://www. scielo.org.co/pdf/hall/v11n21/v11n21n14.pdf

Marín, K. (2017). Estudio de caso Sierra de la Macarena (Meta-Colombia). Estudios Políticos, 51(1), 196-217. Recuperado de http://www.scielo.org.co/pdf/espo/ n51/0121-5167-espo-51-00196.pdf

Meza, G. (2016). Justicia nosótrica para la paz: desde la memoria hacia la utopía. Panorama, 10(18), 40-49. Recuperado de http://journal.poligran.edu.co/index. php/panorama/article/view/642/623

Michel, G. (2003). Ética política zapatista: una utopía para el siglo XXI. México D. F., México: Universidad Autónoma Metropolitana-Xochimilco.

Millán, M. F., y Jiménez, I. (2017). Economía y paz. Colombia en un escenario de posconflicto. Ploutos, 7(1), 24-31. Recuperado de https://journal.universidadean. edu.co/index.php/plou/article/view/1757/1670

Montero, M. (1991). Una orientación para la psicología política en América Latina. Psicología Politica, 3, 27-43. Recuperado de https:/www.uv.es/garzon/ psicologia\%20politica/N3-2.pdf 
Moreno, E. (2017). Educación, conflicto y posconflicto en Colombia. Diálogos de Saberes: Investigaciones y Ciencias Sociales, 46(1), 125-142. Recuperado de https:// dialnet.unirioja.es/servlet/articulo? codigo $=6260867$

Osorio, J. (2015). La educación como pilar del posconflicto. Academia Libre, 12(12), 11-17. Recuperado de http://ojsinvestigacion.unilibrebaq.edu.co/ ojsinvestigacion/index.php/academialibre/article/view/612/583

Osorio, J. (2016). La escuela en escenarios de conflicto: daños y desafíos. Hallazgos, 13(26), 179-191. Recuperado de http://www.scielo.org.co/pdf/hall/v13n26/ v13n26a08.pdf

Pachón, W., Gómez, N., y Méndez, A. (2015). Colombia: educación superior y post-conflicto. Proceso de reconstrucción de tejido social basado en el posconflicto. Revista Internacional de Aprendizaje en la Educación Superior, 2(2), 79-86. Recuperado de https://www.researchgate.net/publication/293826244_ Colombia_educacion_superior_y_post-conflicto_Proceso_de_reconstruccion_ de_tejido_social_basado_en_el_post-conflicto

Palacios, M. (2017). Revisión de la literatura de la relación entre conflicto armado y educación en Colombia. Bogotá D. C., Colombia: Universidad Militar Nueva Granada. Recuperado de https://repository.unimilitar.edu.co/bitstream/ handle/10654/16924/PalaciosTovarMar\%EDaJulieth2017.pdf;jsessionid=091B C6044F070155A6969EA8B183FF04? sequence $=3$

Pérez, T. (2015). Colombia: de la educación en emergencia hacia una educación para el posconflicto y la paz. Revista Interamericana de Investigación, Educación y Pedagogía, RIIEP, 7(2), 287-311. Recuperado de https://revistas.usantotomas. edu.co/index.php/riiep/article/view/1959/2069?locale=pt_BR

Pérez, F. (2016). El papel de la educación en el posconflicto. Recuperado de http://viva. org.co/cajavirtual/svc0496/pdfs/Anexo_1.pdf 
Perfetti, M. (2004). Estudio sobre la educación para la población rural en Colombia. En Organización de las Naciones Unidas para la Alimentación y la Agricultura - FAO, Organización de las Naciones Unidas para la Educación, la Ciencia y la Cultura - Unesco (eds.), Educación para la población rural en Brasil, Chile, Colombia, Honduras, México, Paraguay y Perú (pp. 164-216). Roma, Italia: FAO. Recuperado de https://unesdoc.unesco.org/ark:/48223/pf0000136025_mul

Raczynski, D., y Román, M. (2014). Evaluación de la educación rural. Revista Iberoamericana de Evaluación Educativa, 7(3), 9-14. Recuperado de https:// revistas.uam.es/index.php/riee/article/view/3098/3297

Rivas, H. (2015). El papel que juega la educación secundaria en el conflicto y en el postconflicto colombiano (tesis de posgrado). Universidad Nacional Abierta y a Distancia, Bogotá D. C., Colombia. Recuperado de https://repository.unad.edu. co/handle/10596/3710

Salamanca Ospina, E. (2017). Retorno y paz en contextos de conflicto. Análisis desde el enfoque de la vulnerabilidad social del caso El Carpintero (Colombia) (tesis doctoral). Universidad de Granada, España. Recuperado de http://digibug.ugr. es/bitstream/handle/10481/49225/28879806.pdf;jsessionid=05A052ACADD2 9AC0056CF2905E8EC817? sequence $=1$

Sotelo Amaya, J., Castellanos Londońo, I., y Rodríguez Andrade, R. (2017). La paz: una oportunidad de desarrollo social. Revista de la Universidad de La Salle, 73(2), 209-225. Recuperado de https://ciencia.lasalle.edu.co/cgi/viewcontent. cgi?article $=2117 \&$ context $=$ ruls

Tabla, A. (2015). La pedagogía social en el posconflicto colombiano. Revista Experiencia Docente, 2(2), 9-13. Recuperado de http://experienciadocente.ecci. edu.co/index.php/experienciadoc/article/view/50/37

Tönnies, F. (1942). Principios de sociología. México D. F., México: Fondo de Cultura Económica. 
Tovar, J., y Vélez, L. (2017). La educación y la pedagogía en el escenario del postconflicto en Colombia. Revista de Ciencias de la Educación, Docencia, Investigación y Tecnologías de la Información-Cedotic, 2(1), 1-20. Recuperado de http://investigaciones.uniatlantico.edu.co/revistas/index.php/CEDOTIC/ article/view/1796/1746

Valencia, I., Corredor, O., Jiménez, A., De los Ríos, J., y Salcedo, L. (2016). Pedagogía, educación y paz en escenarios de posconflicto e inclusión social. Revista Lasallista de Investigación, 13(1), 126-140. Recuperado de http://www. redalyc.org/html/695/69545978012/

Vélez, G., Ortega, P., y Merchán, J. (2017). La escuela en ecologías violentas: entre las políticas y la pedagogía de la memoria. Voces y Silencios: Revista Latinoamericana de Educación, 8(1), 187-201. Recuperado de https://revistas.uniandes.edu.co/ doi/full/10.18175/vys8.1.2017.11

Weber, M. (2008). Economía y Sociedad. México D. F., México: Fondo de Cultura Económica.

Yepes Ocampo, J. C. (2016). Retos y dilemas de la educación superior pública en Colombia: procesos de transformación en los últimos cinco lustros. Manizales, Colombia: Universidad de Caldas. 